\title{
Advanced radiation techniques for locally advanced non-small cell lung cancer: intensity-modulated radiation therapy and proton therapy
}

\author{
Nikhil Yegya-Raman ${ }^{1}$, Wei Zou ${ }^{2}, K$ Nie $^{1}$, Jyoti Malhotra ${ }^{3}$, Salma K. Jabbour ${ }^{1}$ \\ ${ }^{1}$ Department of Radiation Oncology, Rutgers Cancer Institute of New Jersey, Rutgers Robert Wood Johnson Medical School, Rutgers University, \\ New Brunswick, NJ, USA; ${ }^{2}$ Department of Radiation Oncology, University of Pennsylvania, Philadelphia, PA, USA; ${ }^{3}$ Division of Medical Oncology, \\ Rutgers Cancer Institute of New Jersey, Rutgers Robert Wood Johnson Medical School, Rutgers University, New Brunswick, NJ, USA \\ Contributions: (I) Conception and design: N Yegya-Raman, SK Jabbour; (II) Administrative support: None; (III) Provision of study materials or \\ patients: None; (IV) Collection and assembly of data: All authors; (V) Data analysis and interpretation: All authors; (VI) Manuscript writing: All \\ authors; (VII) Final approval of manuscript: All authors. \\ Correspondence to: Salma K. Jabbour, MD. Rutgers Cancer Institute of New Jersey, 195 Little Albany Street, New Brunswick, NJ 08903, USA. \\ Email: jabbousk@cinj.rutgers.edu.
}

\begin{abstract}
Radiation therapy (RT) represents an integral part of a multimodality treatment plan in the definitive, preoperative and postoperative management of non-small cell lung cancer (NSCLC). Technological advances in RT have enabled a shift from two-dimensional radiotherapy to more conformal techniques. Three-dimensional conformal radiotherapy (3DCRT), the current minimum technological standard for treating NSCLC, allows for more accurate delineation of tumor burden by using computed tomography-based treatment planning instead of two-dimensional radiographs. Intensity-modulated RT (IMRT) and proton therapy represent advancements over 3DCRT that aim to improve the conformity of RT and provide the possibility for dose escalation to the tumor by minimizing radiation dose to organs at risk. Both techniques likely confer benefits to certain anatomic subgroups of NSCLC requiring RT. This article reviews pertinent studies evaluating the use of IMRT and proton therapy in locally advanced NSCLC, and outlines challenges, indications for use, and areas for future research.
\end{abstract}

Keywords: Non-small cell lung cancer (NSCLC); three-dimensional conformal radiotherapy (3DCRT); intensitymodulated radiation therapy (IMRT); proton therapy; toxicities

Submitted Sep 13, 2017. Accepted for publication Jul 04, 2018.

doi: $10.21037 /$ jtd.2018.07.29

View this article at: http://dx.doi.org/10.21037/jtd.2018.07.29

\section{Introduction}

Lung cancer is the leading cause of cancer deaths in the United States. In 2018, it is estimated that 234,030 new cases will be diagnosed (1), of which about $85 \%$ will represent non-small cell lung cancer (NSCLC). Radiation therapy (RT) remains an integral part of a multimodality treatment plan in the definitive, preoperative and postoperative management of NSCLC. For early stage NSCLC (stage I and selected node negative stage IIA), stereotactic body RT plays an important role, particularly for inoperable cases $(2,3)$. For locally advanced NSCLC (node positive stage II and stage III), current treatment for poor surgical candidates consists of conventionally fractionated RT to 60-70 Gy, delivered concurrently with platinum-based chemotherapy, with consideration for consolidation durvalumab for stage III patients (4-7).

RT first arose as a curative treatment for lung cancer in the 1950's, when treatment fields were designed using two-dimensional (2D) radiographs (8). In the 1980's, computed tomography (CT)-based treatment planning became more widely used and multileaf collimators (MLCs) began replacing Cerrobend blocking, allowing for 
the automation of radiation field shaping. Both CT and MLCs enabled the advent of three-dimensional conformal radiotherapy (3DCRT), which uses planning CT to outline a target volume and permits treatment planning that shapes fields to the tumor volume. By the late 1990's, 3DCRT gained widespread acceptance; it is the current minimum technological standard for treating NSCLC in the United States. Using the Surveillance, Epidemiology and End Results (SEER) database, Chen et al. found that, for patients diagnosed with stage III NSCLC between 2000 and 2005 who received primary RT, CT simulation was associated with a lower risk of death compared with conventional 2D simulation [adjusted hazard ratio (HR), $0.77, \mathrm{P}<0.01](9)$.

Survival benefits observed with modern use of 3DCRT are likely multifactorial in etiology, and not solely due to the inherent advantages of CT over 2D radiographs. The parallel transition from sequential to concurrent chemoradiation regimens, along with the introduction of third-generation chemotherapy agents, has synergized to improve outcomes $(5,10)$. Endobronchial ultrasound and positron emission tomography (PET) scans have refined the ability to clarify involved nodal basins and identify micrometastatic disease, more accurately delineating distant disease burden and permitting appropriate assignment of stage grouping to determine optimal treatment paradigms $(11,12)$. The ability to use involved nodal volumes rather than elective nodal volumes has allowed for higher doses of RT to be delivered to the tumor site $(13,14)$. Image guidance during the course of RT and methods to account for tumor motion have led to more precise tumor targeting and decreased planning target volume (PTV) margins, and may also improve outcomes (15-18).

Despite advancements in treatment modalities for NSCLC, toxicity of thoracic RT remains a significant concern. Tumoricidal doses may be higher than the tolerance of adjacent critical structures including healthy lung parenchyma, esophagus, heart, spinal cord, brachial plexus, and bone marrow. For example, in RTOG 0617, a randomized phase III trial comparing 60 to 74 Gy with concurrent chemotherapy in the treatment of inoperable stage III NSCLC, inferior overall survival (OS) in the 74 Gy arm was partially attributed to higher heart doses and severe esophagitis (4).

Intensity-modulated RT (IMRT) and proton therapy represent advancements over 3DCRT that aim to provide more conformal dose to the tumor site while minimizing dose to surrounding organs at risk (OARs). By increasing selectivity for the tumor over OARs, IMRT and proton therapy offer theoretical advantages over traditional techniques. Potential advantages include decreased treatment-related toxicities, the opportunity for safer dose escalation to achieve superior local control, and the ability to re-irradiate in recurrent cases. Nevertheless, both techniques face a variety of challenges, such as limited evidence establishing superiority and the need for additional resources. This article reviews the pertinent studies evaluating the use of IMRT and proton therapy in locally advanced NSCLC, and outlines challenges, indications for use, and areas for future research.

\section{IMRT}

\section{Background}

IMRT is an advancement over 3DCRT whereby the fluence of radiation across each beam is modified, allowing for more targeted and conformal delivery to the disease site while sparing adjacent OARs. Traditional 3DCRT planning involves forward planning, in which the user manually tests different combinations of beam shapes, weights, and gantry angles to achieve a satisfactory dose distribution. IMRT uses computerized inverse planning, in which the user inputs the desired dose distribution, and the computer uses a cost function to optimize the fluence map of the beams. IMRT fields are segmented into a number of subfields, and beam intensities are varied across different subfields. To achieve an optimal dose distribution, IMRT typically requires 4-12 optimized modulated fields, whereas 3DCRT requires 3-4 unmodulated or less modulated fields $(19,20)$.

Planning studies comparing IMRT to 3DCRT for NSCLC have consistently demonstrated that IMRT allows for superior coverage of the PTV and greater avoidance of healthy lung parenchyma, heart, esophagus and spinal cord (21-29). When designing IMRT plans, beam angle optimization determines which OARs will be preferentially spared. Anterior or posterior beam angles $\pm 45^{\circ}$ allow for more optimal sparing of normal lung, whereas lateral beams prioritize sparing the heart (30). In contrast to 3DCRT, IMRT provides more integral dose and may increase the low-doses delivered to OARs $(24,25)$. Given the more targeted delivery, IMRT provides the theoretical ability to more safely dose escalate to achieve higher biologically effective doses and better local tumor control. 


\section{Modalities}

IMRT delivery using conventional MLCs can be classified as step-and-shoot, sliding window or rotational, based on the number of gantry angles and the relationship between leaf movement and radiation dose delivery. Stepand-shoot and sliding window IMRT are both delivered from a number of fixed gantry angles, but the former only delivers radiation when MLC leaves are stationary while the latter delivers radiation while MLC leaves are in motion. The result is that step-and-shoot IMRT delivers discrete intensity levels and sliding window IMRT delivers continuous intensity levels. Rotational IMRT, including tomotherapy and volumetric-modulated arc therapy (VMAT), delivers radiation with MLCs and gantry both in motion. The radiation source rotates around the patient during radiation delivery, allowing the patient to be treated from the full 360-degree beam angle. Continuous leaf motion and a rotating gantry are theoretically advantageous as they provide more modulation of the beam fluence within the entire arc. However, apart from a reduction in treatment time with VMAT, planning studies in NSCLC indicate no clear advantage of one particular IMRT technique over another (27,31-36). VMAT plans may place greater pressures on the planning team, as they take longer to optimize.

\section{Retrospective clinical studies}

Most studies examining outcomes of IMRT in locally advanced NSCLC are retrospective in nature. Historically, IMRT was typically chosen over 3DCRT for anatomically complex cases (e.g., paraspinal tumors, apical tumors adjacent to the brachial plexus, tumors adjacent to other critical organs, tumors with bilateral mediastinal involvement, or tumors with larger PTVs). Patient selection biases thus might be expected to militate against IMRT, showing more favorable outcomes for 3DCRT. Additionally, the increasing use of simulation with four-dimensional CT (4DCT) and image guidance with cone-beam CT (CBCT) for IMRT patients may affect clinical outcomes data $(17,18)$.

Investigators from MD Anderson Cancer Center (MDACC) conducted the first few retrospective studies. Comparing a cohort of 68 patients treated with IMRT between 2002-2005 to a historical cohort of 222 patients treated with 3DCRT, both to a median dose of 63 Gy and with concurrent chemotherapy, Yom et al. found a lower rate of grade $\geq 3$ treatment-related pneumonitis (TRP) with IMRT (12-month rate, $8 \%$ vs. $32 \%, \mathrm{P}=0.002)$ (37). The results were particularly noteworthy in light of the differences between the IMRT and 3DCRT groups: patients who received IMRT had larger gross tumor volumes (GTVs), more advanced disease stage, and worse performance status. The decrease in TRP in the IMRT group was partially attributed to a lower lung volume receiving at least 20 Gy (lung V20), as prior studies had demonstrated a correlation between TRP and lung V20 in NSCLC (38-42). However, the IMRT group also had a higher median lung V5, consistent with planning studies, and a lung V5 $>70 \%$ was associated with an increased risk of TRP. These findings reignited concerns that the increased number of beam angles of IMRT exposes a larger volume of lung to low doses of radiation, creating a "low-dose bath" that may contribute to pulmonary toxicity and an increase in the risk of secondary malignancies $(43,44)$.

Notwithstanding concerns about the "low-dose bath" due to IMRT, a 2012 follow-up study at MDACC including 165 patients (89\% stage III-IV) treated with IMRT with or without chemotherapy provided further support for the reduced pulmonary toxicity of IMRT (45). Esophageal toxicity and survival (median OS, 1.8 years) compared favorably with historical data from conventional external-beam radiation therapy. Additionally, in an expanded cohort comparing IMRT/4DCT ( $\mathrm{N}=91)$ to 3DCRT/CT $(\mathrm{N}=318)$, again to a median dose of $63 \mathrm{~Gy}$ and with concurrent chemotherapy in both groups, Liao et al. also found a reduction in grade $\geq 3$ TRP and lung V20 with IMRT/4DCT, along with improved OS (median OS, 1.4 vs. 0.85 years, $\mathrm{P}=0.039$ ) (46). Because more patients in the IMRT group were staged with PET/CT, part of this improvement in OS was thought to be a result of stage migration. Other singlecenter retrospective studies found similarly encouraging results with respect to pulmonary toxicity (47-50).

Although single-center retrospective studies found promising results with IMRT despite its use for more advanced disease, population-based retrospective studies showed mixed results. Studies using the SEER database did not show a clear benefit in OS or reduction in pulmonary or esophageal toxicity for IMRT compared to 3DCRT (51-54). Importantly, toxicity data was based on Medicare claims, which does not provide information on toxicity grade. On the other hand, studies using the National Cancer Database (NCDB) showed an improved OS for T3 and T4 locally advanced NSCLC treated with IMRT versus 3DCRT (55), as well as a reduction in RT interruptions (56). Because the NCDB does not collect information on toxicity or 
treatment planning, it is not possible to understand the underlying factors driving the survival benefit.

$\mathrm{Hu}$ et al. conducted a meta-analysis of retrospective studies through April 2015 that compared clinical outcomes between IMRT and 3DCRT (57). On univariate analysis, OS was significantly improved in the IMRT group, but on multivariate analysis there was no survival benefit (HR, 0.96, P=0.477). Furthermore, IMRT was associated with a reduced incidence of grade 2 TRP [relative risk (RR), 0.74, $\mathrm{P}=0.009$ ] and an increased incidence of grade 3 radiation esophagitis ( $\mathrm{RR}, 2.47, \mathrm{P}=0.000$ ). The latter result should be interpreted with caution as analyses of esophagitis were based only on four single-center retrospective studies. Also, it is not clear how OARs were prioritized with respect to dose optimization.

\section{RTOG 0617 and secondary analyses}

A potential advantage of IMRT over 3DCRT is the ability to more safely and effectively escalate radiation dose to possibly improve locoregional control and OS. The transition toward involved field radiation therapy, based on the low rates of elective and involved nodal failures with this strategy $(13,14,58)$, provided a need for highly conformal techniques that can realize the benefits of targeted dose escalation.

Promising results from phase I/II dose escalation trials led to the design of RTOG 0617, a randomized phase III trial comparing $60 \mathrm{~Gy} / 30$ daily fractions to $74 \mathrm{~Gy} / 37$ daily fractions (concurrently with weekly paclitaxel/carboplatin, followed by consolidation chemotherapy), with or without cetuximab, in 544 patients with unresectable stage III NSCLC (4,59-62). Forty-seven percent received IMRT, while the rest received 3DCRT. This was expected to be the first phase III trial to confirm the benefit of dose escalation beyond 60 Gy in stage III NSCLC; instead, high-dose (74 Gy) RT resulted in lower OS compared with conventional-dose (60 Gy) RT (median OS, 20.3 vs. 28.7 months; HR, 1.38, $\mathrm{P}=0.004)$. Heart and esophageal doses were significantly higher in the highdose group, and on multivariate analysis heart V5 and V30, as well as maximum esophagitis grade, predicted for poorer OS.

Two secondary analyses of RTOG 0617 were conducted to compare IMRT and 3DCRT $(63,64)$. Because the choice of RT was not randomized but rather left to the physician's discretion, baseline characteristics between the two groups were uneven. The IMRT group had more stage IIIB/N3 disease, a larger median PTV, and lower education level, yet was more likely to be staged with PET and treated at a high-volume center $(63,65)$. Chun et al. found that 2-year OS (53.2\% vs. $49.4 \%, \mathrm{P}=0.597)$, progression-free survival (25.2\% vs. $27 \%, \mathrm{P}=0.595)$, local failure $(30.8 \%$ vs. $37.1 \%$, $\mathrm{P}=0.498$ ), and distant metastases ( $45.9 \%$ vs. $49.6 \%, \mathrm{P}=0.661$ ) were not different between IMRT and 3DCRT (63). However, those who received IMRT experienced less grade $\geq 3$ TRP $[3.5 \%$ vs. $7.9 \%, \mathrm{P}=0.039$; adjusted odds ratio (OR), $0.41, \mathrm{P}=0.046]$, which may have been due to the marginally lower lung V20 for a given PTV (66). Of note, lung V5 was higher with IMRT but did not predict for grade $\geq 3$ TRP. IMRT also produced lower heart doses (V20, V40, V60; $\mathrm{P}<0.05)$, with higher heart V40 associated with inferior OS on adjusted analyses (HR, 1.012, $\mathrm{P}<0.001)$. Moreover, patients treated with IMRT were more likely to receive full doses of consolidation chemotherapy (37\% vs. $29 \%, \mathrm{P}=0.05)$. The authors contend that long-term follow-up could help to ascertain whether the reduction in TRP and improved heart dose leads to a survival benefit.

In another secondary analysis of RTOG 0617, Movsas et al. examined the effect of radiation dose and use of IMRT on quality of life (QoL) changes (64). QoL was collected prospectively via the validated FACT-Trial Outcome Index. Significantly more patients on the 74 Gy arm than the 60 Gy arm had a clinically meaningful decline (CMD) in QoL at 3 months (45\% vs. 30\%, $\mathrm{P}=0.02$ ). Moreover, fewer IMRT versus 3DCRT patients had a CMD on the Lung Cancer Subscale (21.2\% vs. 46.4\%, $\mathrm{P}=0.003)$. Heart V5 was associated with both OS and CMD in QoL at 12 months.

The secondary analyses of RTOG 0617 suggest that lower heart doses correlate with improved OS and QoL, and that IMRT can better spare the heart than 3DCRT, consistent with the majority of planning studies $(21-24,26,29,63)$. In a pooled analysis of dose escalation trials using 3DCRT to treat stage III NSCLC in the setting of induction/concurrent chemotherapy, Wang et al. found that $23 \%$ of patients experienced a symptomatic cardiac event at a median of 26 months to first event posttreatment, and that higher heart doses and baseline cardiac morbidity predicted for these events (67). Other studies showed a similar relationship between heart doses and posttreatment cardiac (68-71) or pulmonary toxicities (72). Because patients with inoperable NSCLC often have preexisting cardiac disease and/or multiple cardiac risk factors, the reduced heart doses conferred by IMRT treatment plans stand especially clinically relevant. 


\section{Implementation challenges}

The proportion of stage III NSCLC patients treated with IMRT increased from $2 \%$ in 2002 to $25 \%$ in 2009 , while the proportion treated with $2 \mathrm{D}$ radiotherapy (2DRT) decreased from $32 \%$ to $3 \%$ over the same timeframe (53). Although IMRT is used routinely for locally advanced NSCLC, widespread use is limited because of a lack of highquality evidence establishing superiority and the requirement for more advanced delivery systems and dose calculation algorithms. Using data from the SEER registry linked to Medicare claims, Kale et al. estimated that RT-related costs were $\$ 6,850$ higher per patient for IMRT versus 3DCRT (54).

First of all, there is no randomized data comparing IMRT to 3DCRT; all comparative studies are retrospective, with the exception of secondary analyses of RTOG 0617 . Even in RTOG 0617, choice of RT was not randomized, introducing the same biases present in retrospective studies. MDACC is sponsoring a randomized phase II trial comparing time to treatment failure (development of TRP or locoregional recurrence) in locally advanced NSCLC treated with either IMRT or 3DCRT, both with concurrent chemotherapy (NCT00520702). It is ongoing but not recruiting participants.

An additional barrier is that equipment capable of facilitating on-treatment image guided radiotherapy (IGRT) is preferred for IMRT delivery. The increased conformity of IMRT creates a steeper decline in dose outside the PTV. A steeper dose fall-off, especially in the setting of dose escalation, necessitates the use of IGRT, preferably daily, to control for geometric uncertainties such as setup errors and organ motion $(73,74)$. Daily imaging before each fraction reevaluates patient geometry throughout the course of treatment to ensure patient positioning remains identical to that at the initial treatment planning session. Because interfractional changes in tumor volume, mobility and patient setup can lead to significant dosimetric consequences, patients may need to undergo resimulation during the course of RT to modify the GTV $(75,76)$.

Tumor movement due to respiration introduces another level of complexity to IMRT, requiring methods to account for such motion. Using 4DCT, Liu et al. found that $39.2 \%$ of stage III or IV NSCLC tumors move $>5 \mathrm{~mm}$ in the craniocaudal direction during treatment, and $10.8 \%$ move $>1 \mathrm{~cm}$ (77). Although tumors located in the lower lobes generally exhibit greater motion, presumably driven by diaphragmatic movement, the magnitude of motion is variable (78). Variation in tumor location with respiration creates two effects: the gradient/ blurring effect, and the interplay effect. The gradient effect, described as the blurring in location of the tumor as it moves, occurs regardless of radiation technique but may be more relevant with IMRT because of the tendency to reduce PTV margins (79). The interplay effect refers to the asynchrony between inherent tumor motion and MLC leaf motion during radiation delivery. Because IMRT treatment fields may only cover a portion of the target volume at any particular time, the interplay effect has the potential to produce inhomogeneity within the target volume $(80,81)$. Although planning studies have demonstrated that this effect is unlikely to alter the dose distribution with the use of multiple fields and over the course of treatment, concerns still arise regarding potentially unexpected hot or cold spots in or around the target $(79,82,83)$.

With IMRT, motion management and mitigation techniques should be utilized to minimize these effects. Abdominal compression and breath holding can reduce tumor motion, and 4DCT simulation can integrate respiratory movements into treatment planning by creation of an internal target volume (ITV) to account for motion of the tumor (84-87). Respiratory gating and tumor tracking may enable more accurate treatment delivery as well (88).

Since IMRT delivers numerous beamlets that form steep fluence gradients, it also poses the challenge of accurate calculation of dose distribution. The inclusion of correction factors for the heterogeneous density of the lung has been a significant advancement in dose calculation for IMRT (89). Heterogeneity corrections result in more accurate dose evaluation and better conformity $(90,91)$. Currently, there are three main dose calculation algorithms, which, in increasing order of accuracy/sophistication are: type A (pencil beam), type B (convolution/superposition) and type C (Monte Carlo) $(89,92)$. Even with the inclusion of heterogeneity corrections, type A algorithms are unsuitable for NSCLC, particularly when IMRT is used $(90,91,93)$.

\section{Indications/summary}

In the absence of randomized data comparing IMRT to 3DCRT and studies showing a clear benefit in survival or local control with IMRT, along with the increased cost associated with IMRT, 3DCRT may continue to serve as a practical option for certain ipsilateral NSCLC tumors. Nevertheless, studies suggest that IMRT reduces lung V20, pulmonary toxicity, and heart doses, and may improve QoL, despite its use for more unfavorable tumors. Thus, IMRT 
could be especially valuable for treatment of large tumors, tumors with bilateral mediastinal involvement, or tumors in complex anatomic positions abutting OARs such as the heart. Patients with extensive comorbidity, including preexisting cardiovascular disease, may benefit significantly from IMRT. Finally, the role of IMRT in dose escalation remains to be defined.

\section{Proton therapy}

\section{Background}

Unlike photons, protons have mass and a positive elementary charge. These characteristics give protons certain theoretical advantages over photons. Accelerated protons enter the body with a high momentum, carrying them to a specific depth that depends both on the initial speed of the protons as well as the density of the tissue through which they pass. At that specific depth, protons rapidly decelerate, losing energy to surrounding tissues by colliding with electrons of neighboring atoms. The rapid deceleration deposits the dose with a steep falloff, a phenomenon known as the Bragg peak. In contrast, photons deposit dose maximum near the surface and continue along with a decreasing curve throughout the body, resulting in a significant exit dose. The Bragg peak specific to protons improves the conformity of proton therapy, better sparing tissue distal to the tumor depth compared with photons. Additionally, the relative biological effectiveness for proton therapy is estimated as $1.1 \times$ that for photon therapy. Many of the theoretical advantages of IMRT also apply to proton therapy, namely the ability to treat anatomically complex tumors near critical structures as well as to escalate dose to the GTV $(94,95)$.

\section{Modalities}

Proton therapy is currently delivered either as passive scatter proton therapy (PS-PT) or through a pencil-beam scanning (PBS) approach, the latter of which can deliver intensity-modulated proton therapy (IMPT). PS-PT uses a forward planning technique to design a conformal dose distribution. PBS proton therapy, on the other hand, uses an objective function that accounts for targets as well as constraints on normal tissues to modulate the intensities and energies of the pencil beams. The planning process may utilize either single-field optimization or multiplefield optimization, the latter of which allows for IMPT (96).
Unlike photon-based IMRT that typically requires 4-12 beams or VMAT which utilizes constantly changing fields with arc rotation, IMPT typically needs only 2-4 fields (97). The differences between PS-PT and IMPT are analogous to those between 3DCRT and IMRT for photon irradiation. Generally, PS-PT is simpler to plan and less sensitive to motion than IMPT. However, it cannot adjust its modulation width for an irregularly shaped tumor with varying thickness. This may lead to unplanned doses to normal tissue and OARs located proximal to the tumor along the beam path. Thus, IMPT may be best suited for anatomically complex tumors with minimal motion.

\section{Dosimetric studies}

Dosimetric comparisons have consistently demonstrated that proton therapy provides similar, if not superior tumor coverage than photon therapy, while further reducing doses to normal organs (98-102). Giaddui et al. generated PSPT and IMRT plans for 26 patients from RTOG 1308 (NCT01993810), a phase III randomized trial comparing OS after photon versus proton chemoradiotherapy for inoperable locally advanced NSCLC (102). Based on the findings from RTOG 0617 that heart dose correlated with OS, RTOG 1308 was designed with more stringent dosimetric compliance criteria. While dose parameters for the target volume were similar for both plans, PS-PT led to significantly lower lung V5, maximum spinal cord dose, heart V5, heart V30, heart V45, heart V50, and mean heart dose. There was no significant difference in lung V20.

Two planning studies found that, in the setting of dose escalation, PS-PT significantly reduced doses to normal lung, spinal cord, heart and esophagus compared to IMRT and 3DCRT $(103,104)$. The better sparing of OARs persisted even when comparing dose-escalated PS-PT to standard-dose IMRT and 3DCRT (104).

Comparisons between PS-PT and IMPT have shown that IMPT provides greater sparing of critical structures but may be more sensitive to changes in position or anatomy $(96,105,106)$. Zhang et al. observed that compared to IMPT, PS-PT, with its limited number of treatment fields, may be relatively ill-suited for treatment of tumors in select locations such as the contralateral hilum or supraclavicular lymph node region (106).

\section{Clinical studies}

Several studies, published after 2010, have evaluated 
clinical outcomes after proton therapy for locally advanced NSCLC. A retrospective study from MDACC found that the rates of grade $\geq 3$ TRP and esophagitis were $2 \%$ and $5 \%$, respectively, among NSCLC patients (mostly stage III) receiving PS-PT [ $\mathrm{N}=62$, median dose 74 cobalt gray equivalent (CGE)], significantly lower than for casematched controls who received IMRT $(\mathrm{N}=66$, median dose $63 \mathrm{~Gy}$, rates of $9 \%$ and $44 \%$ ) and 3DCRT $(\mathrm{N}=74$, median dose 63 Gy, rates of $30 \%$ and 18\%) (107). Consistent with these findings, a prospective longitudinal observational study at MDACC found that patient-reported esophagitisrelated pain and systemic symptoms were less severe with proton therapy compared with 3DCRT and IMRT (108). All patients in these two studies received concurrent chemotherapy. For patients unsuitable for concurrent chemotherapy, retrospective data from the University of Tsukuba suggests that proton therapy alone (median equivalent dose in 2 Gy/fraction, 78.3 CGE) may be a reasonable option $(109,110)$.

A series of phase II trials showed that high-dose proton therapy concurrent with chemotherapy for stage III NSCLC affords promising clinical outcomes and rates of toxicity compared with historical photon therapy data (Table 1) (111-114). In a final report of their phase II study of proton therapy to a total dose of 74 CGE, Chang et al. found a median OS of 26.5 months, with a crude local recurrence rate of $16 \%$ (113). Rates of grade $\geq 3$ TRP and esophagitis, acute and late, were low. This median OS compares favorably with the median OS of 20.3 months in the high-dose arm of RTOG 0617 (4).

Using the NCDB, Higgins et al. found that proton therapy was administered to only 348 out of 243,822 patients with stage I-IV NSCLC treated with thoracic RT from 2004 to 2012, and more frequently to those from a ZIP code with a median income $\geq \$ 46,000$ per year. Stage II-III patients treated with non-proton therapy versus proton therapy experienced inferior OS on multivariate analysis (HR, 1.35, $\mathrm{P}<0.01)$. On propensity-matched analysis, the survival benefit with proton therapy did not reach significance among stage II-III patients (5-year OS, $17 \%$ for non-proton therapy $v s .22 \%$ for proton therapy, $\mathrm{P}=0.41$ ), but did among stage I-IV patients (5-year OS, $16 \%$ vs. $22 \%, \mathrm{P}=0.025$ ) (115). Despite propensity-matching, patient selection biases in larger databases such as this one may limit interpretation of the findings.

Liao et al. recently published results from the first randomized trial to compare PS-PT $(\mathrm{N}=57)$ to IMRT $(\mathrm{N}=92)$, both delivered concurrently with chemotherapy, for stage IIB-IIIB, stage IV (with a single brain metastasis), or recurrent NSCLC (116). In this trial, investigators created PS-PT and IMRT plans for each patient, randomizing patients only if both plans met normal tissue constraints at the same prescription dose (74 CGE if achievable, otherwise 66 CGE). The cumulative incidence of grade $\geq 3$ TRP or local failure, the primary endpoint, did not differ between groups (12-month rate, $21.1 \%$ for PS-PT vs. $17.4 \%$ for IMRT, $\mathrm{P}=0.175)$. Notably, PS-PT reduced heart doses by all measures and lung volume receiving 5-10 CGE, but exposed more lung to $\geq 20$ CGE. These findings lead to the question of the possible improvements with IMPT with respect to dosimetric and clinical outcomes.

\section{Re-irradiation}

Studies have also investigated proton therapy's possible role in re-irradiation for intrathoracic recurrences, which were historically managed with palliative chemotherapy or palliative photon therapy. Proton therapy is an appealing option in this setting because the rapid dose falloff beyond the Bragg peak has the potential to spare previously irradiated normal tissue.

A report from MDACC of 33 patients with NSCLC who were re-irradiated to a median dose of 66 CGE found 1 -year OS and locoregional control rates of $47 \%$ and $54 \%$, respectively, with grade $\geq 3$ pulmonary and esophageal toxicity occurring in $21 \%$ and $9 \%$, respectively (117). A more recent retrospective study from MDACC of 27 patients (22 of whom had NSCLC) who were re-irradiated with IMPT to a median dose of 66 CGE found 1-year OS and locoregional control rates of $54 \%$ and $61 \%$, respectively, with only $7 \%$ experiencing late grade $\geq 3$ pulmonary toxicity and no patient experiencing grade $\geq 3$ esophagitis (118). Of note, patients who received $\geq 66$ CGE versus <66 CGE experienced superior 1-year locoregional control and PFS rates, suggesting that delivery of definitive doses may confer a measurable benefit. Lastly, a multiinstitutional prospective trial reported outcomes among 57 patients who were re-irradiated for recurrent NSCLC to a median dose of 66.6 CGE (119). At a median followup of 7.8 months, 1-year OS was 59\%, 25\% experienced locoregional recurrence, and $42 \%$ developed grade $\geq 3$ acute or late toxicities. Greater target volume overlap with the central airway, higher mean esophagus and heart doses, and concurrent chemotherapy were associated with higher toxicity rates, suggesting that careful patient selection for re-irradiation is crucial. 
Table 1 Phase II trials of high-dose PT with concurrent chemotherapy for stage III NSCLC

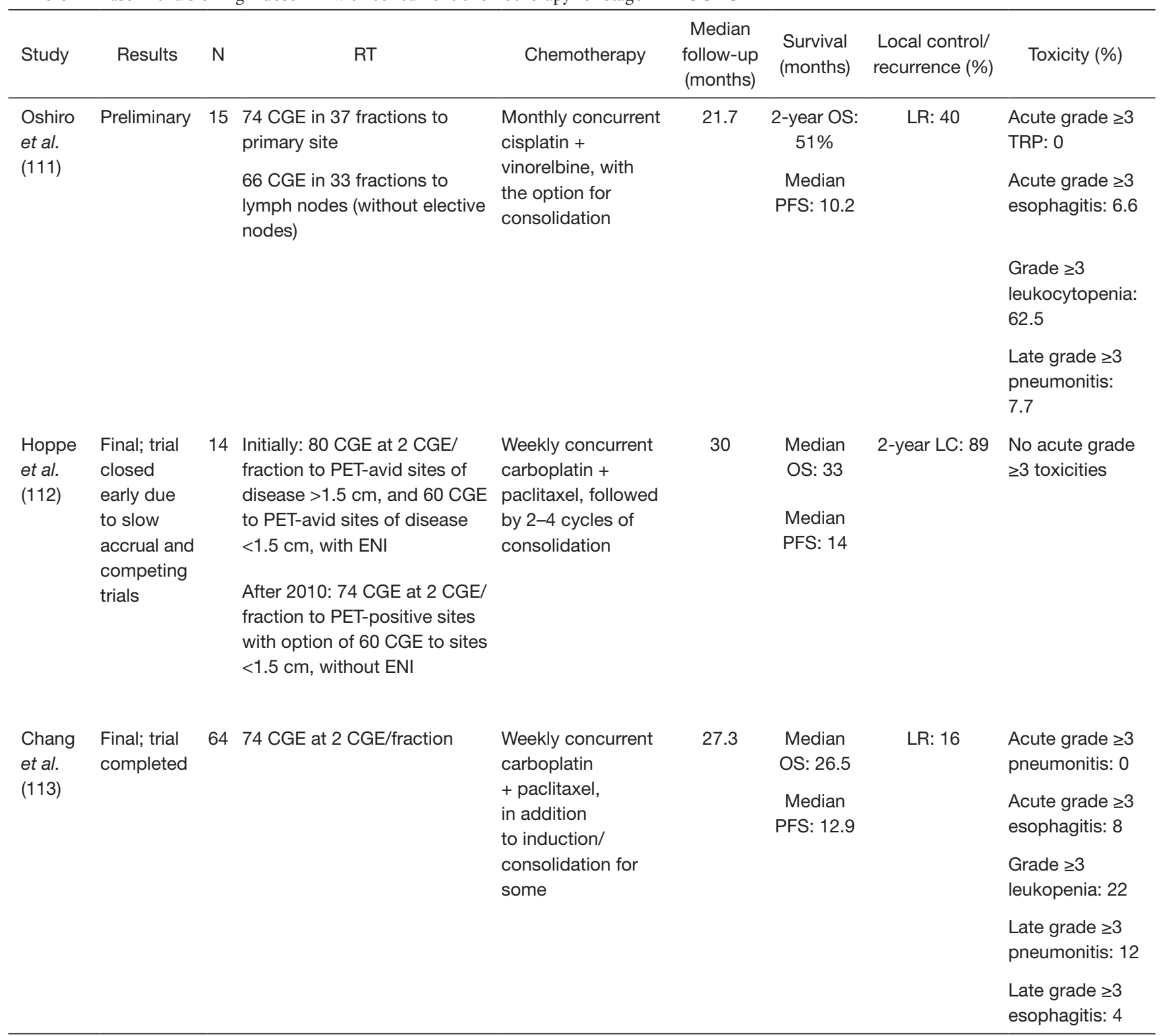

PT, proton therapy; NSCLC, non-small cell lung cancer; CGE, cobalt Gray equivalent; ENI, elective nodal irradiation; OS, overall survival; PFS, progression-free survival; LR, local recurrence; TRP, treatment-related pneumonitis; LC, local control.

\section{Implementation challenges}

Proton therapy faces many of the same challenges as IMRT, including early and limited evidence establishing superiority over traditional radiation techniques, and the need for additional resources and quality assurance. Limited availability, increased cost, and added technical considerations raise further challenges.

A significant source of concern is the added cost; proton therapy is estimated to be 1.6-2.4 times as expensive as photon therapy (120). However, proton therapy may increase quality-adjusted life years (QALYs) in patients with locally advanced NSCLC compared to both 3DCRT and IMRT, and therefore is potentially more cost-effective for locally advanced than for early stage NSCLC $(121,122)$. These conclusions are based on Markov analysis, with limited clinical data. RTOG 1308 aims to more definitively address the question of 

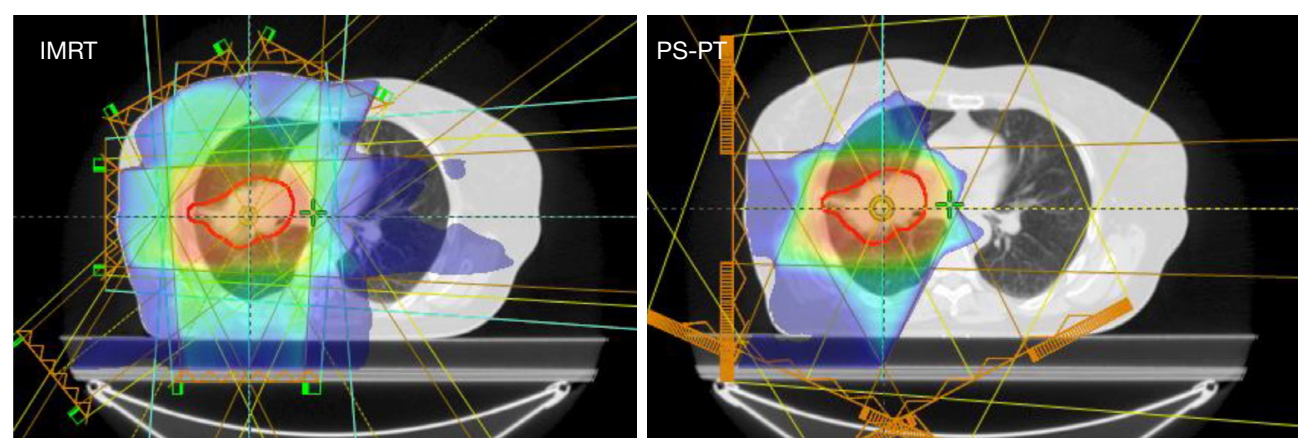

\begin{tabular}{lcc}
\hline Dose to organ at risk & IMRT & PS-PT \\
\hline Mean lung dose & 24.2 Gy & $18.6 \mathrm{~Gy}$ \\
Lung V5 & $78.8 \%$ & $44.6 \%$ \\
Lung V20 & $41.4 \%$ & $38 \%$ \\
Mean heart dose & 14.7 Gy & 5.3 Gy
\end{tabular}

Figure 1 Five-field intensity-modulated radiation therapy (IMRT) plan $v$ s. three-field passive scatter proton therapy (PS-PT) plan for a large stage IIIA non-small cell lung cancer treated with definitive chemoradiation therapy to 60 Gy in 2 Gy per fraction. Unlike PS-PT, IMRT distributes significant exit dose to the left lung and heart. As a result, PS-PT leads to decreased mean lung dose, lung volume receiving at least 5 Gy (V5), and mean heart dose. Both plans depict the 10 Gy colorwash on lung windows on the average scan of the 4-dimensional computed tomography simulation. The red contour outlines the gross tumor volume.

cost-effectiveness on secondary analysis. Additionally, proton therapy may allow for safer hypofractionation, a paradigm with demonstrated cost-effectiveness for photon therapy (123). Moreover, by increasing the therapeutic index, proton therapy could more effectively and selectively treat the initial tumor, decreasing recurrences, toxicity to normal tissue, and long-term morbidity. Each of these factors may decrease long-term hospitalizations and cost of care (124).

From a technical standpoint, characteristics of the Bragg peak make protons more sensitive than photons to uncertainties in respiratory and tumor motion, tissue density changes, changes in patient positioning, and tumor shrinkage $(125,126)$. Compared to IMRT and PSPT, IMPT is even more affected by these uncertainties as a result of the highly modulated fields with steep dose gradients (127-131). The inhomogeneous beam of IMPT, combined with the interplay effect between motion of the scanning beam and respiratory motion, can result in regions of under- or over-treatment. Proton therapy therefore requires the use of many of the same advanced technologies as IMRT: 4DCT-based simulation to evaluate tumor motion, motion management and mitigation procedures, robust optimization and quality assurance measures, on- treatment image guidance, and adaptive-replanning to account for tumor shrinkage and anatomy changes (96). Specific guidelines for the clinical implementation of PBS proton therapy were recently published by the Particle Therapy Co-Operative Group (PTCOG) Thoracic Subcommittee (132).

\section{Indications/summary}

Proton therapy is not considered the standard of care for locally advanced NSCLC, likely because of the limited comparative data to IMRT and 3DCRT, increased cost, and added technical considerations. Nevertheless, dosimetric data suggests both PS-PT and IMPT can better spare certain OARs than IMRT, with IMPT providing the greatest dosimetric benefit but potentially requiring additional adjustments for uncertainties associated with beam range and organ motion. Given the increasing recognition of the importance of heart dose for NSCLC $(133,134)$, proton therapy may provide a benefit over IMRT for certain anatomically challenging tumors on a case-bycase basis (Figures 1,2). Additionally, phase II results suggest proton therapy may help achieve safer dose escalation; however, we await additional comparative data to IMRT 


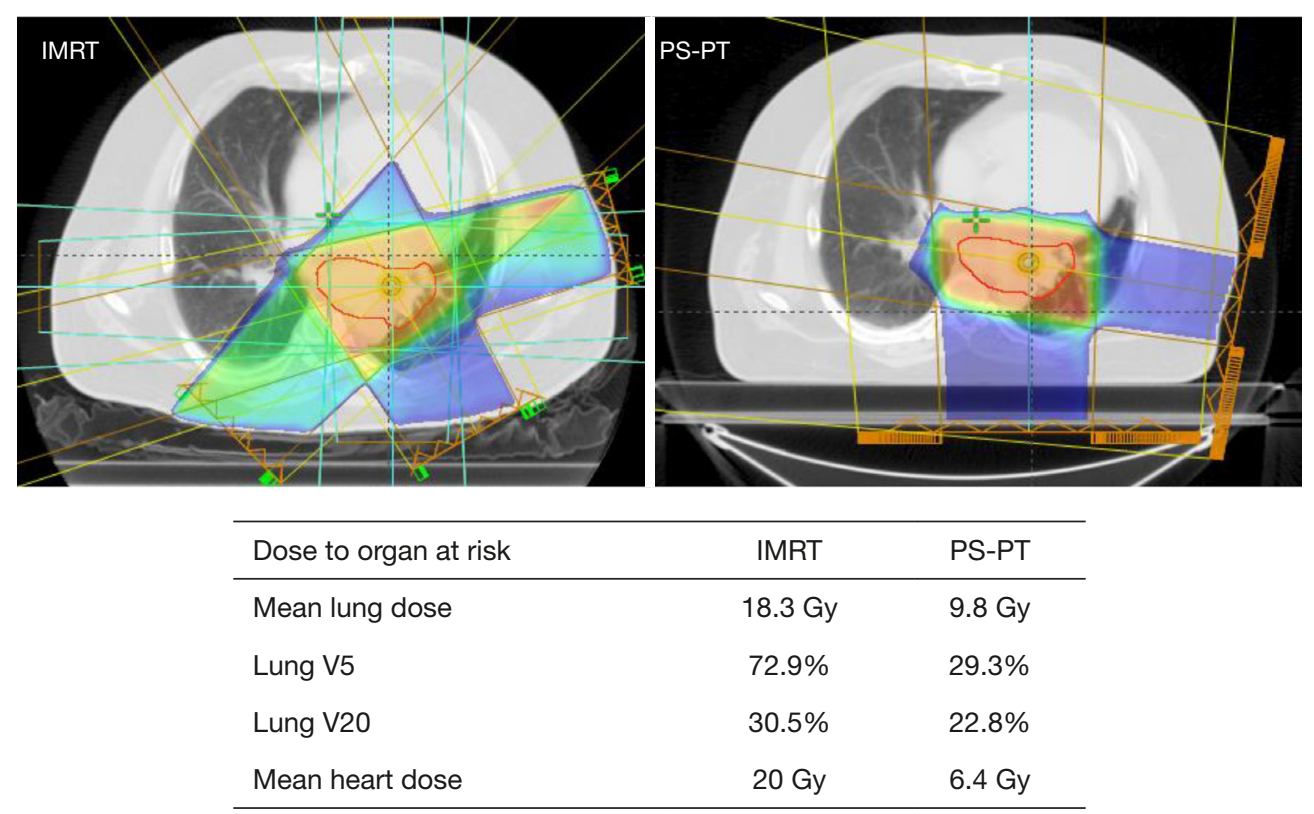

Figure 2 Three-field intensity-modulated radiation therapy (IMRT) plan vs. two-field passive scatter proton therapy (PS-PT) plan for a posterior mediastinal stage IIIA non-small cell lung cancer treated with definitive chemoradiation therapy to 60 Gy in 2 Gy per fraction. Similar to Figure 1, PS-PT demonstrates reduced dose to the heart and lungs compared to IMRT, with decreased mean lung dose, lung volume receiving at least 5 Gy (V5), lung V20, and mean heart dose. Both plans depict the 20 Gy colorwash on lung windows on the average scan of the 4-dimensional computed tomography simulation. The red contour outlines the gross tumor volume.

and 3DCRT. Finally, re-irradiation with proton therapy appears feasible for carefully selected patients.

\section{Future directions}

Current research is aiming to advance technologies needed to safely and feasibly implement IMRT and proton therapy, and clearly define which subgroups of patients may benefit the most. Results from RTOG 0617 indicate that dose escalation may not be the appropriate option for all locally advanced NSCLC patients. To this end, several clinical trials are providing selective dose intensification with IMRT, using either functional imaging to identify patients at high risk of local failure or isotoxic radiotherapy to ascertain the maximum achievable biologically effective dose for each patient based on dose constraints to OARs (Table 2). Parallel refinements in treatment planning systems are underway, particularly the novel highly non-coplanar $4 \pi$ system that has yielded improvements in plan quality over VMAT for large and centrally located tumors in the setting of dose escalation (135). Ongoing clinical trials aim to further define proton therapy's role in dose escalation and re-irradiation, and provide comparisons to IMRT (Table 3). With the increasing use of motion-control procedures and volumetric image guidance, along with the recently published guidelines by the PTCOG (132), future studies should establish the safety and clinical efficacy of the more advanced IMPT.

\section{Conclusions}

From 2DRT to 3DCRT, IMRT and proton therapy, technological advances in radiation modalities have revolutionized the treatment of locally advanced NSCLC, enabling for more conformal RT delivery. IMRT can improve the therapeutic ratio compared to 3DCRT, decreasing dose to OARs and reducing pulmonary toxicity. Proton therapy can further reduce dose to OARs, particularly the heart, and is starting to define its role in dose escalation and re-irradiation. The increased cost and additional resources needed to safely deliver both techniques should not serve as a barrier to use, but rather as motivation to more clearly define which subset of patients benefit most from each modality. Results from ongoing clinical trials 


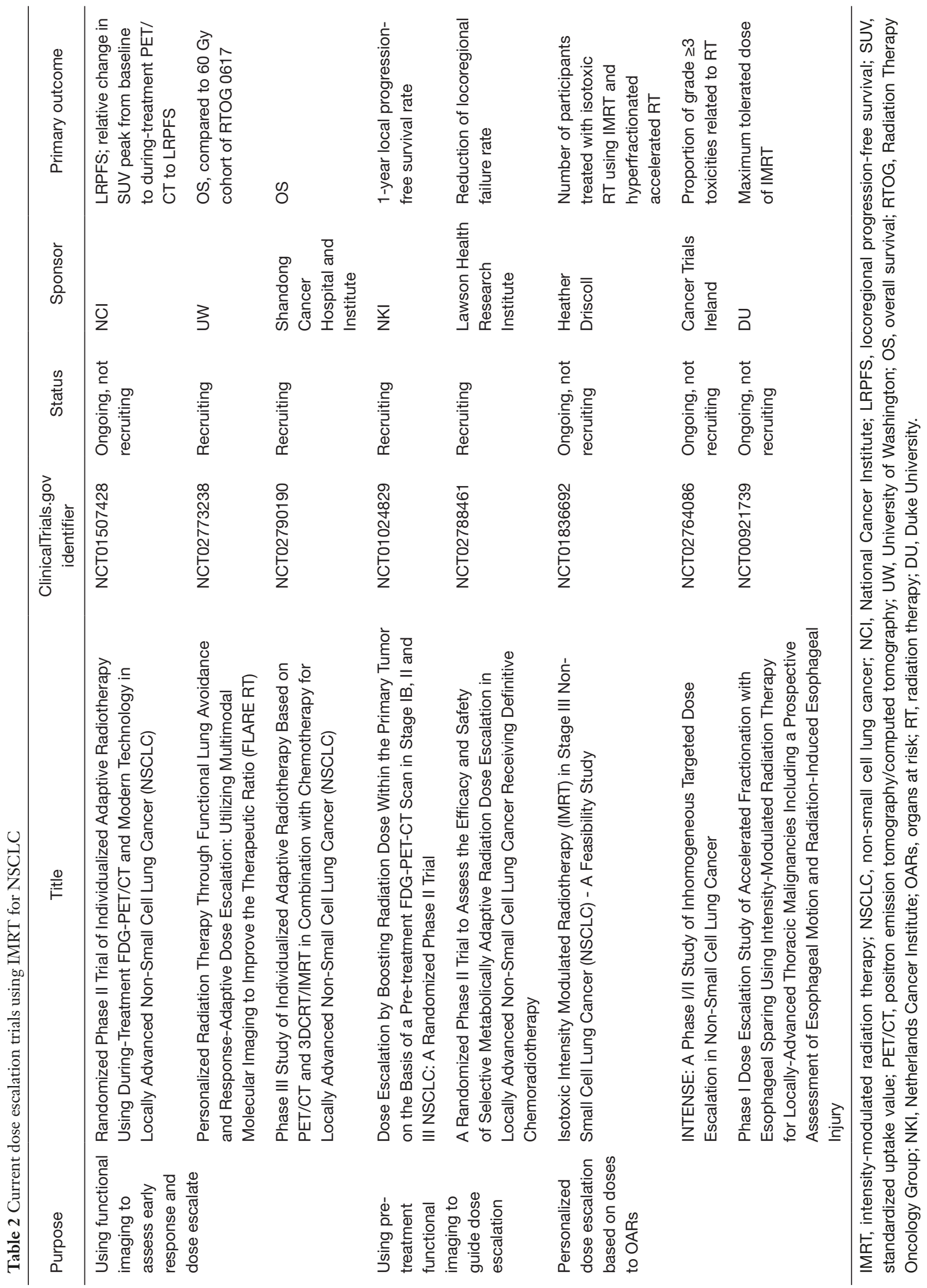




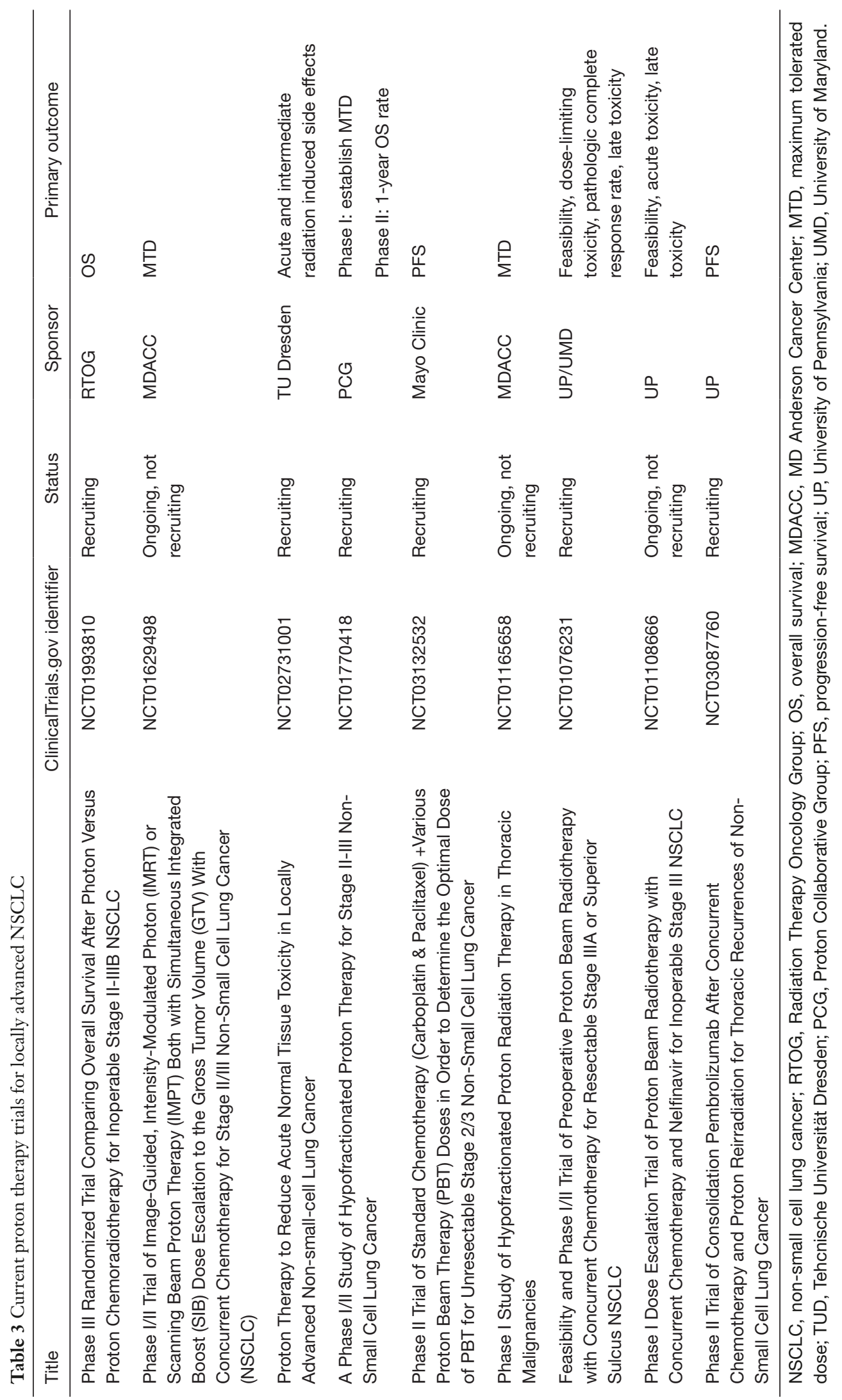


should help to guide future research and further push the boundaries of radiation techniques for years to come.

\section{Acknowledgements}

None.

\section{Footnote}

Conflicts of Interest: SK Jabbour has research funding from Merck and Nestle. The other authors have no conflicts of interest to declare.

\section{References}

1. Siegel RL, Miller KD, Jemal A. Cancer statistics, 2018. CA Cancer J Clin 2018;68:7-30.

2. Timmerman R, Paulus R, Galvin J, et al. Stereotactic body radiation therapy for inoperable early stage lung cancer. JAMA 2010;303:1070-6.

3. Videtic GMM, Donington J, Giuliani M, et al. Stereotactic body radiation therapy for early-stage non-small cell lung cancer: Executive Summary of an ASTRO Evidence-Based Guideline. Pract Radiat Oncol 2017;7:295-301.

4. Bradley JD, Paulus R, Komaki R, et al. Standard-dose versus high-dose conformal radiotherapy with concurrent and consolidation carboplatin plus paclitaxel with or without cetuximab for patients with stage IIIA or IIIB non-smallcell lung cancer (RTOG 0617): a randomised, two-by-two factorial phase 3 study. Lancet Oncol 2015;16:187-99.

5. Curran WJ Jr, Paulus R, Langer CJ, et al. Sequential vs. concurrent chemoradiation for stage III non-small cell lung cancer: randomized phase III trial RTOG 9410. J Natl Cancer Inst 2011;103:1452-60.

6. Antonia SJ, Villegas A, Daniel D, et al. Durvalumab after Chemoradiotherapy in Stage III Non-Small-Cell Lung Cancer. N Engl J Med 2017;377:1919-29.

7. National Comprehensive Cancer Network. Non-Small Cell Lung Cancer (Version 4.2018). Accessed June 25th, 2018. Available online: https://www.nccn.org/ professionals/physician_gls/pdf/nscl.pdf

8. Jaklitsch MT, Strauss GM, Healey EA, et al. An historical perspective of multi-modality treatment for resectable non-small cell lung cancer. Lung Cancer 1995;12 Suppl 2:S17-32.

9. Chen AB, Neville BA, Sher DJ, et al. Survival outcomes after radiation therapy for stage III non-small-cell lung cancer after adoption of computed tomography-based simulation. J Clin Oncol 2011;29:2305-11.

10. Baggstrom MQ, Stinchcombe TE, Fried DB, et al. Thirdgeneration chemotherapy agents in the treatment of advanced non-small cell lung cancer: a meta-analysis. J Thorac Oncol 2007;2:845-53.

11. Morgensztern D, Goodgame B, Baggstrom MQ, et al. The effect of FDG-PET on the stage distribution of nonsmall cell lung cancer. J Thorac Oncol 2008;3:135-9.

12. Dinan MA, Curtis LH, Carpenter WR, et al. Stage migration, selection bias, and survival associated with the adoption of positron emission tomography among medicare beneficiaries with non-small-cell lung cancer, 1998-2003. J Clin Oncol 2012;30:2725-30.

13. Rosenzweig KE, Sura S, Jackson A, et al. Involved-field radiation therapy for inoperable non small-cell lung cancer. J Clin Oncol 2007;25:5557-61.

14. Rosenzweig KE, Sim SE, Mychalczak B, et al. Elective nodal irradiation in the treatment of non-small-cell lung cancer with three-dimensional conformal radiation therapy. Int J Radiat Oncol Biol Phys 2001;50:681-5.

15. Grills IS, Hugo G, Kestin LL, et al. Image-guided radiotherapy via daily online cone-beam CT substantially reduces margin requirements for stereotactic lung radiotherapy. Int J Radiat Oncol Biol Phys 2008;70:1045-56.

16. Deek MP, Kim S, Yue N, et al. Modern radiotherapy using image guidance for unresectable non-small cell lung cancer can improve outcomes in patients treated with chemoradiation therapy. J Thorac Dis 2016;8:2602-9.

17. Yegya-Raman N, Kim S, Deek MP, et al. Daily Image Guidance with Cone Beam Computed Tomography May Reduce Radiation Pneumonitis in Unresectable NonSmall Cell Lung Cancer. Int J Radiat Oncol Biol Phys 2018. [Epub ahead of print].

18. Kilburn JM, Soike MH, Lucas JT, et al. Image guided radiation therapy may result in improved local control in locally advanced lung cancer patients. Pract Radiat Oncol 2016;6:e73-80.

19. Webb S. Intensity-Modulated Radiation Therapy. Series in Medical Physics and Biomedical Engineering. CRC Press, 2015.

20. Intensity Modulated Radiation Therapy Collaborative Working G. Intensity-modulated radiotherapy: current status and issues of interest. Int J Radiat Oncol Biol Phys 2001;51:880-914.

21. Boyle J, Ackerson B, Gu L, et al. Dosimetric advantages of intensity modulated radiation therapy in locally advanced lung cancer. Adv Radiat Oncol 2017;2:6-11.

22. Woodford K, Panettieri V, Ruben JD, et al. Limiting the 
risk of cardiac toxicity with esophageal-sparing intensity modulated radiotherapy for locally advanced lung cancers. J Thorac Dis 2016;8:942-9.

23. Cattaneo GM, Dell'oca I, Broggi S, et al. Treatment planning comparison between conformal radiotherapy and helical tomotherapy in the case of locally advanced-stage NSCLC. Radiother Oncol 2008;88:310-8.

24. Chan OS, Lee MC, Hung AW, et al. The superiority of hybrid-volumetric arc therapy (VMAT) technique over double arcs VMAT and 3D-conformal technique in the treatment of locally advanced non-small cell lung cancer-a planning study. Radiother Oncol 2011;101:298-302.

25. Liu HH, Wang X, Dong L, et al. Feasibility of sparing lung and other thoracic structures with intensitymodulated radiotherapy for non-small-cell lung cancer. Int J Radiat Oncol Biol Phys 2004;58:1268-79.

26. Murshed H, Liu HH, Liao Z, et al. Dose and volume reduction for normal lung using intensity-modulated radiotherapy for advanced-stage non-small-cell lung cancer. Int J Radiat Oncol Biol Phys 2004;58:1258-67.

27. Simeonova A, Abo-Madyan Y, El-Haddad M, et al. Comparison of anisotropic aperture based intensity modulated radiotherapy with $3 \mathrm{D}$-conformal radiotherapy for the treatment of large lung tumors. Radiother Oncol 2012;102:268-73.

28. Christian JA, Bedford JL, Webb S, et al. Comparison of inverse-planned three-dimensional conformal radiotherapy and intensity-modulated radiotherapy for non-small-cell lung cancer. Int J Radiat Oncol Biol Phys 2007;67:735-41.

29. Bree I, van Hinsberg MG, van Veelen LR. High-dose radiotherapy in inoperable nonsmall cell lung cancer: comparison of volumetric modulated arc therapy, dynamic IMRT and 3D conformal radiotherapy. Med Dosim 2012;37:353-7.

30. Chang JY. Intensity-modulated radiotherapy, not 3 dimensional conformal, is the preferred technique for treating locally advanced lung cancer. Semin Radiat Oncol 2015;25:110-6.

31. Chan C, Lang S, Rowbottom C, et al. Intensity-modulated radiotherapy for lung cancer: current status and future developments. J Thorac Oncol 2014;9:1598-608.

32. Bertelsen A, Hansen O, Brink C. Does VMAT for treatment of NSCLC patients increase the risk of pneumonitis compared to IMRT ? - a planning study. Acta Oncol 2012;51:752-8.

33. Jiang X, Li T, Liu Y, et al. Planning analysis for locally advanced lung cancer: dosimetric and efficiency comparisons between intensity-modulated radiotherapy
(IMRT), single-arc/partial-arc volumetric modulated arc therapy (SA/PA-VMAT). Radiat Oncol 2011;6:140.

34. Ong CL, Verbakel WF, Cuijpers JP, et al. Stereotactic radiotherapy for peripheral lung tumors: a comparison of volumetric modulated arc therapy with 3 other delivery techniques. Radiother Oncol 2010;97:437-42.

35. Weyh A, Konski A, Nalichowski A, et al. Lung SBRT: dosimetric and delivery comparison of RapidArc, TomoTherapy, and IMR. J Appl Clin Med Phys 2013;14:4065.

36. Holt A, van Vliet-Vroegindeweij C, Mans A, et al. Volumetric-modulated arc therapy for stereotactic body radiotherapy of lung tumors: a comparison with intensitymodulated radiotherapy techniques. Int J Radiat Oncol Biol Phys 2011;81:1560-7.

37. Yom SS, Liao Z, Liu HH, et al. Initial evaluation of treatment-related pneumonitis in advanced-stage nonsmall-cell lung cancer patients treated with concurrent chemotherapy and intensity-modulated radiotherapy. Int J Radiat Oncol Biol Phys 2007;68:94-102.

38. Graham MV, Purdy JA, Emami B, et al. Clinical dosevolume histogram analysis for pneumonitis after $3 \mathrm{D}$ treatment for non-small cell lung cancer (NSCLC). Int J Radiat Oncol Biol Phys 1999;45:323-9.

39. Wang S, Liao Z, Wei X, et al. Analysis of clinical and dosimetric factors associated with treatment-related pneumonitis (TRP) in patients with non-small-cell lung cancer (NSCLC) treated with concurrent chemotherapy and three-dimensional conformal radiotherapy (3D-CRT). Int J Radiat Oncol Biol Phys 2006;66:1399-407.

40. Palma DA, Senan S, Tsujino K, et al. Predicting radiation pneumonitis after chemoradiation therapy for lung cancer: an international individual patient data meta-analysis. Int J Radiat Oncol Biol Phys 2013;85:444-50.

41. Bradley JD, Hope A, El Naqa I, et al. A nomogram to predict radiation pneumonitis, derived from a combined analysis of RTOG 9311 and institutional data. Int J Radiat Oncol Biol Phys 2007;69:985-92.

42. Hernando ML, Marks LB, Bentel GC, et al. Radiationinduced pulmonary toxicity: a dose-volume histogram analysis in 201 patients with lung cancer. Int J Radiat Oncol Biol Phys 2001;51:650-9.

43. Stathakis S, Roland T, Papanikolaou N, et al. A prediction study on radiation-induced second malignancies for IMRT treatment delivery. Technol Cancer Res Treat 2009;8:141-8.

44. Yorke ED, Jackson A, Rosenzweig KE, et al. Correlation of dosimetric factors and radiation pneumonitis for nonsmall-cell lung cancer patients in a recently completed 
dose escalation study. Int J Radiat Oncol Biol Phys 2005;63:672-82.

45. Jiang ZQ, Yang K, Komaki R, et al. Long-term clinical outcome of intensity-modulated radiotherapy for inoperable non-small cell lung cancer: the MD Anderson experience. Int J Radiat Oncol Biol Phys 2012;83:332-9.

46. Liao ZX, Komaki RR, Thames HD Jr, et al. Influence of technologic advances on outcomes in patients with unresectable, locally advanced non-small-cell lung cancer receiving concomitant chemoradiotherapy. Int J Radiat Oncol Biol Phys 2010;76:775-81.

47. Sura S, Gupta V, Yorke E, et al. Intensity-modulated radiation therapy (IMRT) for inoperable non-small cell lung cancer: the Memorial Sloan-Kettering Cancer Center (MSKCC) experience. Radiother Oncol 2008;87:17-23.

48. Govaert SL, Troost EG, Schuurbiers OC, et al. Treatment outcome and toxicity of intensity-modulated (chemo) radiotherapy in stage III non-small cell lung cancer patients. Radiat Oncol 2012;7:150.

49. Uyterlinde W, Belderbos J, Baas C, et al. Prediction of acute toxicity grade $\geq 3$ in patients with locally advanced non-small-cell lung cancer receiving intensity modulated radiotherapy and concurrent low-dose Cisplatin. Clin Lung Cancer 2013;14:541-8.

50. Wang J, Zhou Z, Liang J, et al. Intensity-Modulated Radiation Therapy May Improve Local-Regional Tumor Control for Locally Advanced Non-Small Cell Lung Cancer Compared with Three-Dimensional Conformal Radiation Therapy. Oncologist 2016;21:1530-7.

51. Shirvani SM, Jiang J, Gomez DR, et al. Intensity modulated radiotherapy for stage III non-small cell lung cancer in the United States: predictors of use and association with toxicities. Lung Cancer 2013;82:252-9.

52. Chen AB, Li L, Cronin A, et al. Comparative effectiveness of intensity-modulated versus $3 \mathrm{D}$ conformal radiation therapy among medicare patients with stage III lung cancer. J Thorac Oncol 2014;9:1788-95.

53. Harris JP, Murphy JD, Hanlon AL, et al. A populationbased comparative effectiveness study of radiation therapy techniques in stage III non-small cell lung cancer. Int J Radiat Oncol Biol Phys 2014;88:872-84.

54. Kale MS, Mhango G, Bonomi M, et al. Cost of Intensitymodulated Radiation Therapy for Older Patients with Stage III Lung Cancer. Ann Am Thorac Soc 2016;13:1593-9.

55. Jegadeesh N, Liu Y, Gillespie T, et al. Evaluating IntensityModulated Radiation Therapy in Locally Advanced NonSmall-Cell Lung Cancer: Results from the National Cancer Data Base. Clin Lung Cancer 2016;17:398-405.
56. Koshy M, Malik R, Spiotto M, et al. Association between intensity modulated radiotherapy and survival in patients with stage III non-small cell lung cancer treated with chemoradiotherapy. Lung Cancer 2017;108:222-7.

57. $\mathrm{Hu} \mathrm{X}, \mathrm{He} \mathrm{W}$, Wen $\mathrm{S}$, et al. Is IMRT Superior or Inferior to 3DCRT in Radiotherapy for NSCLC? A Meta-Analysis. PLoS One 2016;11:e0151988.

58. Li R, Yu L, Lin S, et al. Involved field radiotherapy (IFRT) versus elective nodal irradiation (ENI) for locally advanced non-small cell lung cancer: a meta-analysis of incidence of elective nodal failure (ENF). Radiat Oncol 2016;11:124.

59. Bradley JD, Bae K, Graham MV, et al. Primary analysis of the phase II component of a phase I/II dose intensification study using three-dimensional conformal radiation therapy and concurrent chemotherapy for patients with inoperable non-small-cell lung cancer: RTOG 0117. J Clin Oncol 2010;28:2475-80.

60. Schild SE, McGinnis WL, Graham D, et al. Results of a Phase I trial of concurrent chemotherapy and escalating doses of radiation for unresectable non-small-cell lung cancer. Int J Radiat Oncol Biol Phys 2006;65:1106-11.

61. Socinski MA, Blackstock AW, Bogart JA, et al. Randomized phase II trial of induction chemotherapy followed by concurrent chemotherapy and dose-escalated thoracic conformal radiotherapy (74 Gy) in stage III non-small-cell lung cancer: CALGB 30105. J Clin Oncol 2008;26:2457-63.

62. Stinchcombe TE, Lee CB, Moore DT, et al. Long-term follow-up of a phase I/II trial of dose escalating threedimensional conformal thoracic radiation therapy with induction and concurrent carboplatin and paclitaxel in unresectable stage IIIA/B non-small cell lung cancer. J Thorac Oncol 2008;3:1279-85.

63. Chun SG, Hu C, Choy H, et al. Impact of IntensityModulated Radiation Therapy Technique for Locally Advanced Non-Small-Cell Lung Cancer: A Secondary Analysis of the NRG Oncology RTOG 0617 Randomized Clinical Trial. J Clin Oncol 2017;35:56-62.

64. Movsas B, Hu C, Sloan J, et al. Quality of Life Analysis of a Radiation Dose-Escalation Study of Patients with NonSmall-Cell Lung Cancer: A Secondary Analysis of the Radiation Therapy Oncology Group 0617 Randomized Clinical Trial. JAMA Oncol 2016;2:359-67.

65. Eaton BR, Pugh SL, Bradley JD, et al. Institutional Enrollment and Survival Among NSCLC Patients Receiving Chemoradiation: NRG Oncology Radiation Therapy Oncology Group (RTOG) 0617. J Natl Cancer Inst 2016;108. doi: 10.1093/jnci/djw034.

66. Chun SG, Hu C, Choy H, et al. Comparison of 3-D 
Conformal and Intensity Modulated Radiation Therapy Outcomes for Locally Advanced Non-Small Cell Lung Cancer in NRG Oncology/RTOG 0617. Int J Radiat Oncol Biol Phys 2015;93:S1-2.

67. Wang K, Eblan MJ, Deal AM, et al. Cardiac Toxicity After Radiotherapy for Stage III Non-Small-Cell Lung Cancer: Pooled Analysis of Dose-Escalation Trials Delivering 70 to 90 Gy. J Clin Oncol 2017;35:1387-94.

68. Dess RT, Sun Y, Matuszak MM, et al. Cardiac Events After Radiation Therapy: Combined Analysis of Prospective Multicenter Trials for Locally Advanced Non-Small-Cell Lung Cancer. J Clin Oncol 2017;35:1395-402.

69. Ning MS, Tang L, Gomez DR, et al. Incidence and Predictors of Pericardial Effusion After Chemoradiation Therapy for Locally Advanced Non-Small Cell Lung Cancer. Int J Radiat Oncol Biol Phys 2017;99:70-9.

70. Speirs CK, DeWees TA, Rehman S, et al. Heart Dose Is an Independent Dosimetric Predictor of Overall Survival in Locally Advanced Non-Small Cell Lung Cancer. J Thorac Oncol 2017;12:293-301.

71. Yegya-Raman N, Wang K, Kim S, et al. Dosimetric Predictors of Symptomatic Cardiac Events after Conventional-Dose Chemoradiation Therapy for Inoperable Non-Small Cell Lung Cancer. J Thorac Oncol 2018. [Epub ahead of print].

72. Deek MP, Nagarajan S, Kim S, et al. Clinical characteristics and dose-volume histogram parameters associated with the development of pleural effusions in non-small cell lung cancer patients treated with chemoradiation therapy. Acta Oncol 2016;55:1029-35.

73. Higgins J, Bezjak A, Hope A, et al. Effect of imageguidance frequency on geometric accuracy and setup margins in radiotherapy for locally advanced lung cancer. Int J Radiat Oncol Biol Phys 2011;80:1330-7.

74. Bissonnette JP, Purdie TG, Higgins JA, et al. Conebeam computed tomographic image guidance for lung cancer radiation therapy. Int J Radiat Oncol Biol Phys 2009;73:927-34.

75. Britton KR, Starkschall G, Liu H, et al. Consequences of anatomic changes and respiratory motion on radiation dose distributions in conformal radiotherapy for locally advanced non-small-cell lung cancer. Int J Radiat Oncol Biol Phys 2009;73:94-102.

76. Khalil AA, Knap MM, Petersen MT, et al. Adaptive radiotherapy reduces pneumonitis without increasing the risk of failure in lung cancer. Radiother Oncol 2017;123:S70.

77. Liu HH, Balter P, Tutt T, et al. Assessing respiration- induced tumor motion and internal target volume using fourdimensional computed tomography for radiotherapy of lung cancer. Int J Radiat Oncol Biol Phys 2007;68:531-40.

78. Stevens CW, Munden RF, Forster KM, et al. Respiratorydriven lung tumor motion is independent of tumor size, tumor location, and pulmonary function. Int $\mathrm{J}$ Radiat Oncol Biol Phys 2001;51:62-8.

79. Bortfeld T, Jiang SB, Rietzel E. Effects of motion on the total dose distribution. Semin Radiat Oncol 2004;14:41-51.

80. Riley C, Yang Y, Li T, et al. Dosimetric evaluation of the interplay effect in respiratory-gated RapidArc radiation therapy. Med Phys 2014;41:011715.

81. Ong C, Verbakel WF, Cuijpers JP, et al. Dosimetric impact of interplay effect on RapidArc lung stereotactic treatment delivery. Int J Radiat Oncol Biol Phys 2011;79:305-11.

82. Chui CS, Yorke E, Hong L. The effects of intra-fraction organ motion on the delivery of intensity-modulated field with a multileaf collimator. Med Phys 2003;30:1736-46.

83. Berbeco RI, Pope CJ, Jiang SB. Measurement of the interplay effect in lung IMRT treatment using EDR2 films. J Appl Clin Med Phys 2006;7:33-42.

84. Webb S. Motion effects in (intensity modulated) radiation therapy: a review. Phys Med Biol 2006;51:R403-25.

85. Rosenzweig KE, Hanley J, Mah D, et al. The deep inspiration breath-hold technique in the treatment of inoperable non-small-cell lung cancer. Int J Radiat Oncol Biol Phys 2000;48:81-7.

86. Mah D, Hanley J, Rosenzweig KE, et al. Technical aspects of the deep inspiration breath-hold technique in the treatment of thoracic cancer. Int J Radiat Oncol Biol Phys 2000;48:1175-85.

87. Keall PJ, Mageras GS, Balter JM, et al. The management of respiratory motion in radiation oncology report of AAPM Task Group 76. Med Phys 2006;33:3874-900.

88. Giraud P, Yorke E, Jiang S, et al. Reduction of organ motion effects in IMRT and conformal 3D radiation delivery by using gating and tracking techniques. Cancer Radiother 2006;10:269-82.

89. Chen WZ, Xiao Y, Li J. Impact of dose calculation algorithm on radiation therapy. World J Radiol 2014;6:874-80.

90. Davidson SE, Ibbott GS, Prado KL, et al. Accuracy of two heterogeneity dose calculation algorithms for IMRT in treatment plans designed using an anthropomorphic thorax phantom. Med Phys 2007;34:1850-7.

91. Verma T, Painuly NK, Mishra SP, et al. Performance Evaluation of Algorithms in Lung IMRT: A comparison of Monte Carlo, Pencil Beam, Superposition, Fast 
Superposition and Convolution Algorithms. J Biomed Phys Eng 2016;6:127-38.

92. Zhou C, Bennion N, Ma R, et al. A comprehensive dosimetric study on switching from a Type-B to a Type-C dose algorithm for modern lung SBRT. Radiat Oncol 2017;12:80.

93. Vanderstraeten B, Reynaert N, Paelinck L, et al. Accuracy of patient dose calculation for lung IMRT: A comparison of Monte Carlo, convolution/superposition, and pencil beam computations. Med Phys 2006;33:3149-58.

94. Delaney TF, Kooy HM. Proton and charged particle radiotherapy. Philadelphia, PA: Lippincott Williams and Wilkins, 2008.

95. Gerweck LE, Kozin SV. Relative biological effectiveness of proton beams in clinical therapy. Radiother Oncol 1999;50:135-42.

96. Chang JY, Li H, Zhu XR, et al. Clinical implementation of intensity modulated proton therapy for thoracic malignancies. Int J Radiat Oncol Biol Phys 2014;90:809-18.

97. Chang JY, Jabbour SK, De Ruysscher D, et al. Consensus Statement on Proton Therapy in Early-Stage and Locally Advanced Non-Small Cell Lung Cancer. Int J Radiat Oncol Biol Phys 2016;95:505-16.

98. Wang C, Nakayama H, Sugahara S, et al. Comparisons of dose-volume histograms for proton-beam versus 3-D conformal $\mathrm{x}$-ray therapy in patients with stage I non-small cell lung cancer. Strahlenther Onkol 2009;185:231-4.

99. Wu CT, Motegi A, Motegi K, et al. Dosimetric comparison between proton beam therapy and photon radiation therapy for locally advanced non-small cell lung cancer. Jpn J Clin Oncol 2016. [Epub ahead of print]

100. Macdonald OK, Kruse JJ, Miller JM, et al. Proton beam radiotherapy versus three-dimensional conformal stereotactic body radiotherapy in primary peripheral, early-stage non-small-cell lung carcinoma: a comparative dosimetric analysis. Int J Radiat Oncol Biol Phys 2009;75:950-8.

101. Nichols RC, Huh SN, Henderson RH, et al. Proton radiation therapy offers reduced normal lung and bone marrow exposure for patients receiving dose-escalated radiation therapy for unresectable stage iii non-smallcell lung cancer: a dosimetric study. Clin Lung Cancer 2011;12:252-7.

102. Giaddui T, Chen W, Yu J, et al. Establishing the feasibility of the dosimetric compliance criteria of RTOG 1308: phase III randomized trial comparing overall survival after photon versus proton radiochemotherapy for inoperable stage II-IIIB NSCLC. Radiat Oncol 2016;11:66.
103. Roelofs E, Engelsman M, Rasch C, et al. Results of a multicentric in silico clinical trial (ROCOCO): comparing radiotherapy with photons and protons for non-small cell lung cancer. J Thorac Oncol 2012;7:165-76.

104. Chang JY, Zhang X, Wang X, et al. Significant reduction of normal tissue dose by proton radiotherapy compared with three-dimensional conformal or intensity-modulated radiation therapy in Stage I or Stage III non-small-cell lung cancer. Int J Radiat Oncol Biol Phys 2006;65:1087-96.

105.Hoffmann L, Alber M, Jensen MF, et al. Adaptation is mandatory for intensity modulated proton therapy of advanced lung cancer to ensure target coverage. Radiother Oncol 2017;122:400-5.

106.Zhang X, Li Y, Pan X, et al. Intensity-modulated proton therapy reduces the dose to normal tissue compared with intensity-modulated radiation therapy or passive scattering proton therapy and enables individualized radical radiotherapy for extensive stage IIIB non-small-cell lung cancer: a virtual clinical study. Int J Radiat Oncol Biol Phys 2010;77:357-66.

107. Sejpal S, Komaki R, Tsao A, et al. Early findings on toxicity of proton beam therapy with concurrent chemotherapy for nonsmall cell lung cancer. Cancer 2011;117:3004-13.

108. Wang XS, Shi Q, Williams LA, et al. Prospective Study of Patient-Reported Symptom Burden in Patients With NonSmall-Cell Lung Cancer Undergoing Proton or Photon Chemoradiation Therapy. J Pain Symptom Manage 2016;51:832-8.

109. Nakayama H, Satoh H, Sugahara S, et al. Proton Beam Therapy of Stage II and III Non-Small-Cell Lung Cancer. Int J Radiat Oncol Biol Phys 2011;81:979-84.

110. Oshiro Y, Mizumoto M, Okumura T, et al. Results of Proton Beam Therapy without Concurrent Chemotherapy for Patients with Unresectable Stage III Non-small Cell Lung Cancer. J Thorac Oncol 2012;7:370-5.

111. Oshiro Y, Okumura T, Kurishima K, et al. High-dose concurrent chemo-proton therapy for Stage III NSCLC: preliminary results of a Phase II study. J Radiat Res 2014;55:959-65.

112. Hoppe BS, Henderson R, Pham D, et al. A Phase 2 Trial of Concurrent Chemotherapy and Proton Therapy for Stage III Non-Small Cell Lung Cancer: Results and Reflections Following Early Closure of a Single-Institution Study. Int J Radiat Oncol Biol Phys 2016;95:517-22.

113. Chang JY, Verma V, Li M, et al. Proton Beam Radiotherapy and Concurrent Chemotherapy for Unresectable Stage III Non-Small-Cell Lung Cancer: Final Results of a Phase 2 Study. JAMA Oncol 2017;3:e172032. 
114. Chang JY, Komaki R, Lu C, et al. Phase 2 study of highdose proton therapy with concurrent chemotherapy for unresectable stage III nonsmall cell lung cancer. Cancer 2011;117:4707-13.

115. Higgins KA, O'Connell K, Liu Y, et al. National Cancer Database Analysis of Proton Versus Photon Radiation Therapy in Non-Small Cell Lung Cancer. Int J Radiat Oncol Biol Phys 2017;97:128-37.

116. Liao Z, Lee JJ, Komaki R, et al. Bayesian Adaptive Randomization Trial of Passive Scattering Proton Therapy and Intensity-Modulated Photon Radiotherapy for Locally Advanced Non-Small-Cell Lung Cancer. J Clin Oncol 2018;36:1813-22.

117. McAvoy SA, Ciura KT, Rineer JM, et al. Feasibility of proton beam therapy for reirradiation of locoregionally recurrent non-small cell lung cancer. Radiother Oncol 2013;109:38-44.

118. Ho JC, Nguyen QN, Li H, et al. Reirradiation of thoracic cancers with intensity modulated proton therapy. Pract Radiat Oncol 2018;8:58-65.

119. Chao HH, Berman AT, Simone CB 2nd, et al. MultiInstitutional Prospective Study of Reirradiation with Proton Beam Radiotherapy for Locoregionally Recurrent Non-Small Cell Lung Cancer. J Thorac Oncol 2017;12:281-92.

120. Goitein M, Jermann M. The relative costs of proton and X-ray radiation therapy. Clin Oncol (R Coll Radiol) 2003;15:S37-50.

121.Verma V, Mishra MV, Mehta MP. A systematic review of the cost and cost-effectiveness studies of proton radiotherapy. Cancer 2016;122:1483-501.

122. Verma V, Shah C, Rwigema JC, et al. Costcomparativeness of proton versus photon therapy. Chin Clin Oncol 2016;5:56.

123. Ramaekers BL, Joore MA, Lueza B, et al. Cost effectiveness of modified fractionation radiotherapy versus conventional radiotherapy for unresected non-small-cell lung cancer patients. J Thorac Oncol 2013;8:1295-307.

124. Kutikova L, Bowman L, Chang S, et al. The economic burden of lung cancer and the associated costs of treatment failure in the United States. Lung Cancer 2005;50:143-54.

125. Albertini F, Bolsi A, Lomax AJ, et al. Sensitivity of intensity modulated proton therapy plans to changes in patient weight. Radiother Oncol 2008;86:187-94.

126.Zhao L, Sandison GA, Farr JB, et al. Dosimetric impact of intrafraction motion for compensator-based proton therapy of lung cancer. Phys Med Biol 2008;53:3343-64.

127.Lomax AJ. Intensity modulated proton therapy and its sensitivity to treatment uncertainties 1: the potential effects of calculational uncertainties. Phys Med Biol 2008;53:1027-42.

128. Lomax AJ. Intensity modulated proton therapy and its sensitivity to treatment uncertainties 2: the potential effects of inter-fraction and inter-field motions. Phys Med Biol 2008;53:1043-56.

129. Stuschke M, Kaiser A, Pottgen C, et al. Potentials of robust intensity modulated scanning proton plans for locally advanced lung cancer in comparison to intensity modulated photon plans. Radiother Oncol 2012;104:45-51.

130. Grassberger C, Dowdell S, Lomax A, et al. Motion interplay as a function of patient parameters and spot size in spot scanning proton therapy for lung cancer. Int J Radiat Oncol Biol Phys 2013;86:380-6.

131. Matney J, Park PC, Bluett J, et al. Effects of respiratory motion on passively scattered proton therapy versus intensity modulated photon therapy for stage III lung cancer: are proton plans more sensitive to breathing motion? Int J Radiat Oncol Biol Phys 2013;87:576-82.

132. Chang JY, Zhang X, Knopf A, et al. Consensus guidelines for implementing pencil beam scanning proton therapy for thoracic malignancies on behalf of PTCOG thoracic and lymphoma subcommittee. Int J Radiat Oncol Biol Phys 2017;99:41-50.

133. Urbanic JJ, McGarry RC, Daly ME, et al. Locally Advanced Lung Cancer: Is It Time to Take Cardiac Protection Seriously in Radiation Planning? Int J Radiat Oncol Biol Phys 2018;100:1091-4.

134. Simone CB 2nd. New Era in Radiation Oncology for Lung Cancer: Recognizing the Importance of Cardiac Irradiation. J Clin Oncol 2017;35:1381-3.

135. Dong P, Lee P, Ruan D, et al. 4pi noncoplanar stereotactic body radiation therapy for centrally located or larger lung tumors. Int J Radiat Oncol Biol Phys 2013;86:407-13.

Cite this article as: Yegya-Raman N, Zou W, Nie K, Malhotra J, Jabbour SK. Advanced radiation techniques for locally advanced non-small cell lung cancer: intensitymodulated radiation therapy and proton therapy. J Thorac Dis 2018;10(Suppl 21):S2474-S2491. doi: 10.21037/jtd.2018.07.29 